\title{
A New E-Learning System Focusing on Emotional Aspect
}

\author{
Saromporn CHAROENPIT*, Salinla CHEVAKIDAGARN** and Michiko OHKURA*** \\ * Graduate School of Engineering, Shibaura Institute of Technology, 3-7-5 Toyosu, Koto-ku, Tokyo 135-8548, Japan \\ ** Faculty of Information Technology, Thai-Nichi Institute of Technology, Pattanakarn Rd., Suanluang, Bangkok 10250, Thailand \\ *** College of Engineering, Shibaura Institute of Technology, 3-7-5 Toyosu, Koto-ku, Tokyo 135-8548, Japan
}

\begin{abstract}
E-learning is the computer and network-enabled transfer of skills and knowledge. In e-learning systems, even though few researches on such systems have investigated learner emotions. Research has proposed systems that provide functions to analyze such learner emotions as boredom, interest, or sadness. Unlike previous work, we propose a new e-learning system that considers attention, motivation, satisfaction, enjoyment, interest, anxiety, frustration, scare and tiring. We designed and implemented a prototype experimentally evaluated it, and confirmed that emotional aspects are important in e-learning.
\end{abstract}

Keywords: E-learning, Emotion

\section{INTRODUCTION}

E-learning is an innovation technology that provide a strategy to improve the quality of teaching and learning anytime and anywhere. It has becomes heavily learnercentered and emphasizes pervasive and personalized learning technologies. As more and more technological tools become available for online education, interest will increase among educators and other professionals in their application in online courses [1].

E-learning provides many benefits. During recessions, its case becomes even stronger. Key benefits include low cost, fast delivery, self-paced, reduced travel time, personalized and convenient scheduling, and lower environmental impact.

Previous e-learning studies not only generated good learning outcomes but also more fully engaged learners in the learning process [2]. The importance of emotions in education has been illustrated and researched in many ways through traditional classroom teaching. In engaged learning perspectives, engaged learners are behaviorally, intellectually, and emotionally involved in their learning tasks. In e-learning systems, emotions are important for instructors to create a positive, emotionally safe classroom environment to provide optimal learning. Learning how to manage feelings and relationships constitutes a kind of emotional intelligence that nourishes success [3]. Therefore, how emotions evolve during the learning process and the emotion feedback that was returned to learners can be used to improve learning experiences.

Many higher education institutions have implemented learning management systems (LMSs) to manage online learning and teaching. Providing varying levels of support to staff and students improves the speed and the effectiveness of educational processes and communication among learners as well as among staff and students [1].

In this study, we focused on the emotional aspects of e-learning system. We experimentally designed, implemented, and evaluated a learning environment and a tool that avoids ineffective affective states, such as boredom, anxiety, or anger.

\section{LITERATURE REVIEW}

Goleman, the author of Emotional Intelligence, argues that emotional quotient (EQ) is more important than intelligence quotient (IQ) [4]. Therefore, the issue for e-learning is to recommend ways to keep it from being boring. We recognize that e-learning is different from face-to-face instruction because it lacks a trainer who addresses the emotional component. We provide sensible advice for keeping e-learning relevant.

Khan developed a framework for e-learning that contained the following eight dimensions [5]:

- E-learning's pedagogical dimension, which refers to teaching and learning, addresses issues concerning content, audience, goal, and media analyses, design approach, organization and methods, and strategies of e-learning environments.

- The technological dimension of the e-learning framework examines the technology infrastructure issue in e-learning environments. This includes infrastructure planning, hardware and software.

- The interface design refers to the overall look and feel of the e-learning programs. This dimension 
encompasses the page and site designs, the content design, navigation, and usability testing.

- E-learning evaluation assesses both learners and the instruction and learning environments.

- E-learning management maintains the learning environment and distributes information.

- The resource support dimension of the e-learning framework examines the online support and resources required to foster meaningful learning environments.

- E-learning's ethical considerations are related to social and political influence, bias, cultural, geographical, and learner diversity, information accessibility, etiquette, and legal issues.

- The institutional dimension is concerned with issues of administrative affairs, academic affairs, and student services related to e-learning.

This framework provides a new e-learning system.

As identified by different researches, Kittanakere et al. summarized the main goals of e-learning systems [6]:

- Focus on active learning.

- Accommodate various learning styles.

- Explicitly place the responsibility for learning on the students themselves.

- Develop written and oral communication skills.

- Clarify the teacher's role as facilitator and mentor.

- Provide better coverage of class material.

- Develop a sense of self-confidence and independence in students.

- Encourage peer review.

- Develop interpersonal communication skills when students are geographically distant.

- Support the entire educational process when students are separated both geographically and temporally.

- Teach time management, especially meeting deadlines.

Kittanakere et al. introduced an emotion sensitive e-learning system that emphasizes the complete learning process and is very cost effective. It categorizes a learner's emotional state as happy, neutral, or sad. This stimulates thought about incorporating emotional aspects of teaching in e-learning systems to make them more intelligent. An intelligent e-learning system should be able to adapt to the knowledge, learning abilities, and needs of each learner. Such flexibility offers the feeling of individual care, which supports in the learning process.

Russell developed this circumplex model to describe a user's emotion space [7]. The basic set includes the most important and frequently occurring emotions during learning: interest, engagement, confusion, frustration, boredom, hopefulness, satisfaction, and disappointment.
We used this model to analyze learner emotions.

Kaiser and Oertel also integrated an emotion recognition sensor system (EREC) into an e-learning system [8]. Their system uses EREC, which was developed at the Institute of Genetics and Development of Rennes (IGD$\mathrm{R}$ ), to detect emotions by affective components that consist of a sensor glove, a chest belt, and a data collection unit. The affective components are based on Russell's circumplex model of emotion, which is a dimensional approach for classifying emotions.

$\mathrm{Hu}$ also integrated an e-learning performance evaluation system [9], which included two technology platforms for blog and online testing systems. The blog system evaluates learning processes to motivate learning awareness and provides real-time feedback of evaluation information. The online testing system evaluates the learning result of a certain period to helps students summarize what they have learned and experienced in the learning process.

Joanne et al. formally evaluated the module's phase using the outcome levels of Kirkpatrick's framework [10]:

- Level one: assessment of learner satisfaction with educational intervention. This involves a courseware evaluation survey (CES) developed to evaluate participant satisfaction based on five variables.

- Level two: student learning. This involves a multicenter randomized controlled study using pre and post-test knowledge before and after residents used the module.

- Level three: assessment of training transfer. This involves a retrospective pre and post questionnaires, which are commonly used for quantitative analysis in medical education research.

- Level four: outcomes, which examined the effects on the environment resulting from the application of training.

Chin-Yeh et al. also designed two kinds of humorous performances that were learning-relevant to help students remember [11]. One appeared at the end of every learning video, and the other appeared when the students expressed emotions. They used paper-and-pencil materials that consisted of a pre-test, a post-test, and a questionnaire. The computerized materials consisted of a multimedia computer program for teaching Chinese history.

Based on these literature reviews, we designed a new e-learning system that focuses on learner emotions using questionnaires. Our learning system helps learners deal with negative emotions such as boredom, anxiety, or anger and to keep their attention and enhance their learning motivation, interest, and performance. 


\section{DESIGN OF NEW E-LEARNING SYSTEM}

We used an e-learning framework [5] with the eight dimensions described in Section 2. These dimensions encompass various online learning aspects, including pedagogical, technological, interface design, evaluation, management, resource support, ethical, and institutional issues. Various factors discussed in the framework's eight dimensions can provide guidance in the design, development, delivery, and evaluation of flexibility.

Our system uses an LMS for delivering, tracking, and managing education and a web server that provides users with easy access by a web browser on a personal computer (Figures 1 and 2).

The design of our new e-learning system consists of four modules: learners, instructors, servers, and analysis of learner emotions (Figure 1). The details are described below:

1. Learners: individuals who register for takes up e-learning by the e-learning system and can choose any of the courses provided by the LMS

2. Instructors: a critical element of this system. They create and design courses, content, tests, quizzes, and evaluations in LMS.

3. Servers: web, LMS, and database. The details are described below:

a) Web server dispenses web pages as they are requested from the LMS.

b) Database server provides database services to the LMS.
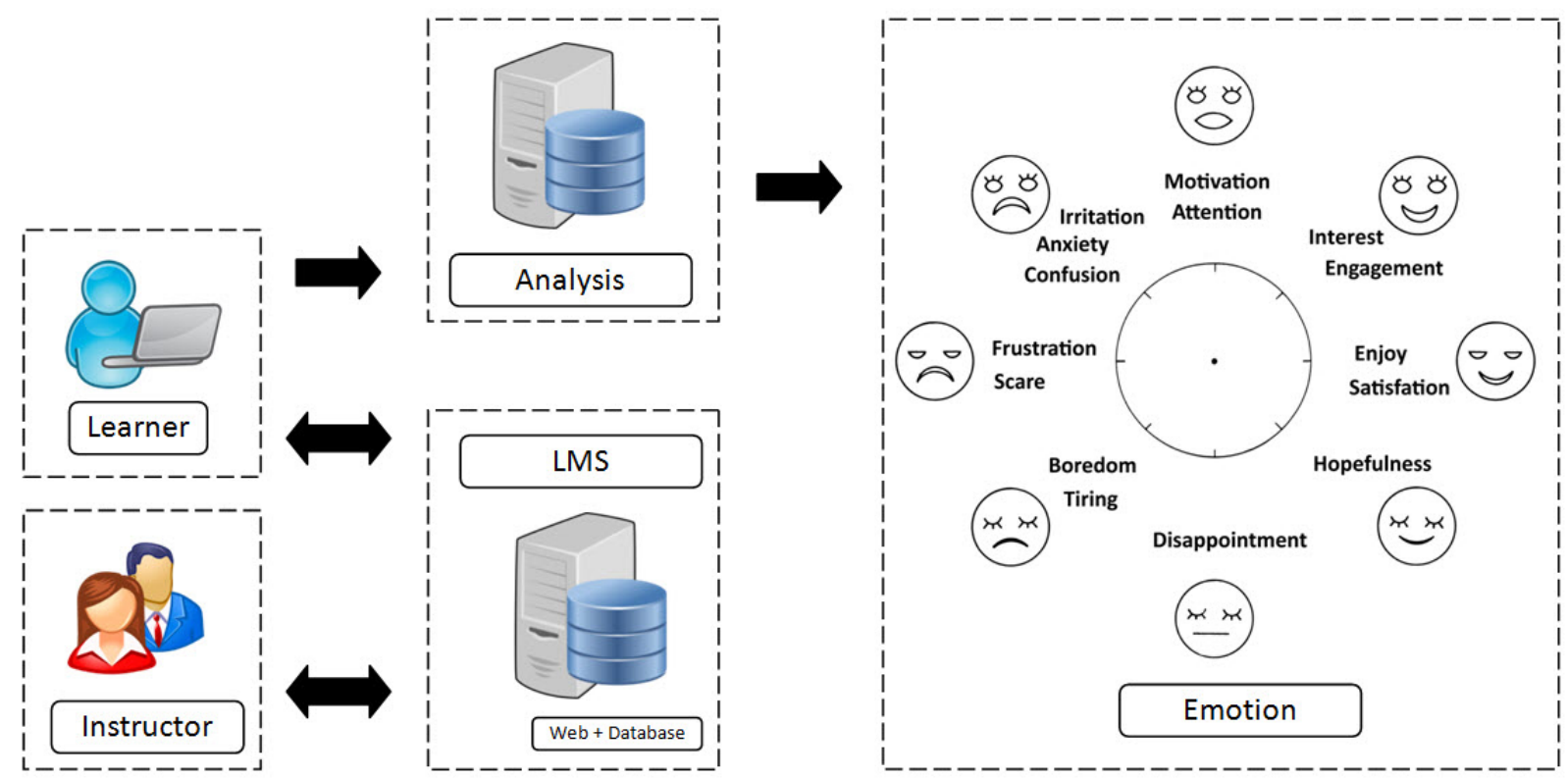

Figure 1: Proposed e-learning system

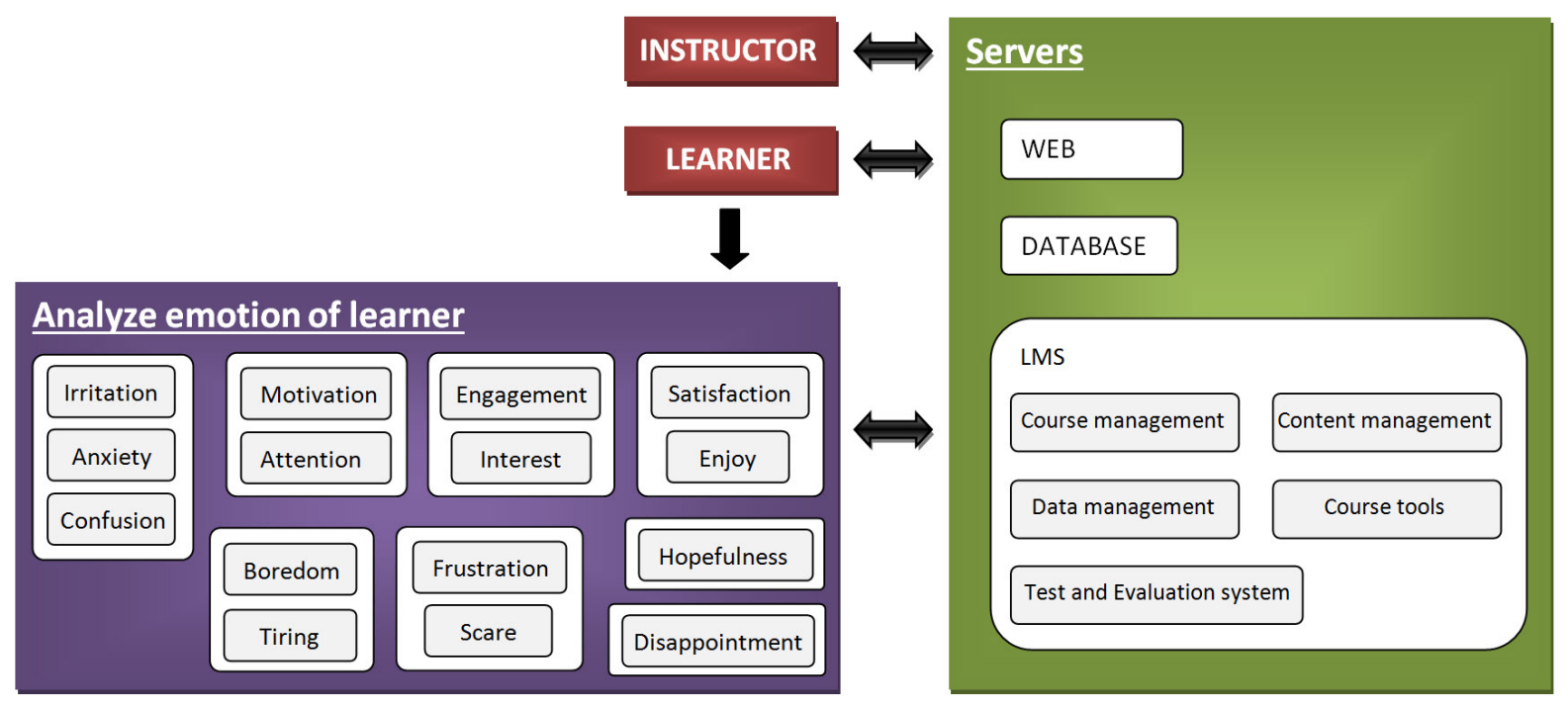

Figure 2: Framework design 
c) The LMS is a web-based technology that plans, implements, and assesses a specific learning process. Typically, it provides an instructor with a way to create and deliver content, monitor student participation, and assess performance. An LMS consists of the following five parts (Figure 2):

- Course management helps store, organize, and communicate a course's information. It consists of two user groups, learners and instructors, that can access the system anytime and anywhere.

- Content management includes tools for creating and supporting the content.

- The test and evaluation system manages exams, interactive quizzes, and integrated tests in the database system to evaluate the learners.

- Course tools are used to help and guide each user.

- The data management system manages the files and folders of each user.

4. Analysis of learner's emotion. We devised this system to understand how learner emotions evolve during the learning process to develop learning systems that recognize and respond appropriately to their emotional changes. We used a questionnaire design [11] and Russell's circumplex model to describe the learner's emotion space [7, 8] (Figure 3).

\section{EXPERIMENT}

\subsection{Experiment Method}

Based on previous research [9-11], we built a prototype of our new e-learning system, which consists of a series of lessons, pre-tests, post-tests, and questionnaires for teaching $\mathrm{C}$ programming for control. We prepared two

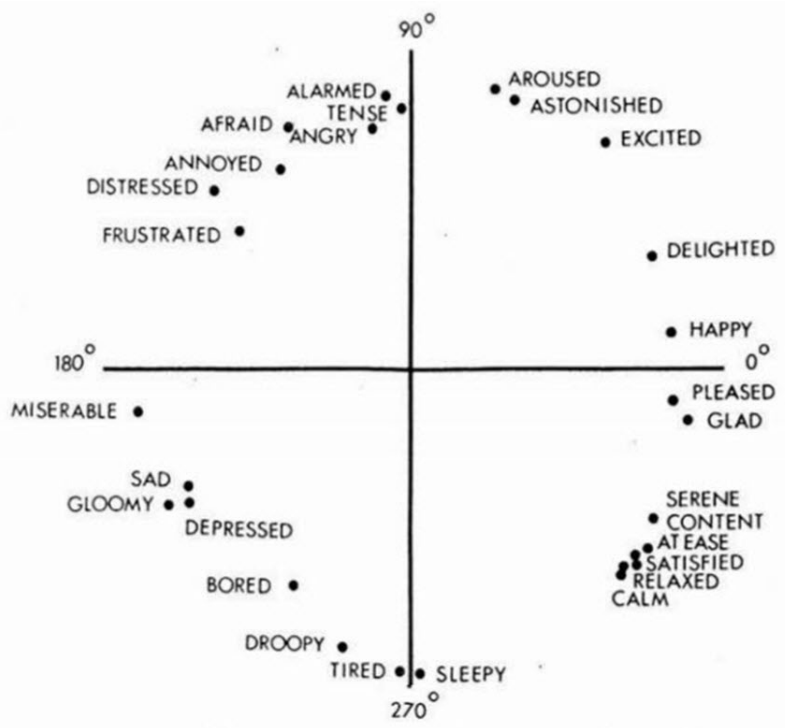

Figure 3: Russell's circumplex model [7]

lesson patterns (Table 1). The process of each is shown in Figure 4, and the details are described below:

- Pattern I: the learners study C programming for control in lesson 1 by power point (PPT) and in lesson 2 by video.

- Pattern II: they learns C programming for control in lesson 1 by video and in lesson 2 by PPT.

The PPT and video designs are shown in Table 2 and described below:

- The PPT design includes text and cartoon. Learners can control the content flow by pushing the enter button.

- The video design runs automatically and includes text, cartoon, and voice.

Table 1: Lesson patterns

\begin{tabular}{|c|c|c|}
\hline Lesson & Pattern I & Pattern II \\
\hline 1 & PPT & Video \\
\hline 2 & Video & PPT \\
\hline
\end{tabular}

Table 2: Design details of PPT and video

\begin{tabular}{|c|c|c|}
\hline Detail & PPT & Video \\
\hline Cartoon & Static & With movement \\
\hline Voice & None & Yes \\
\hline Control & Push enter button & Automatic \\
\hline
\end{tabular}

Pattern I

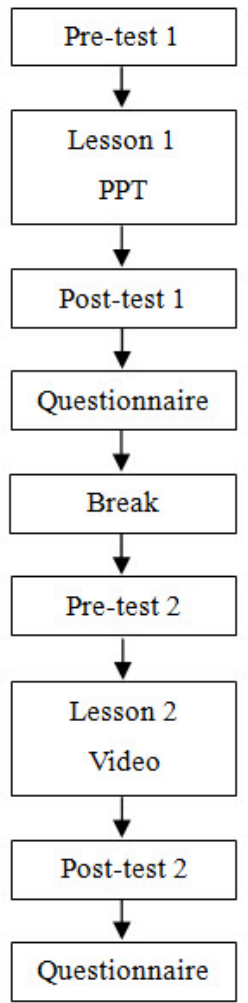

Pattern II

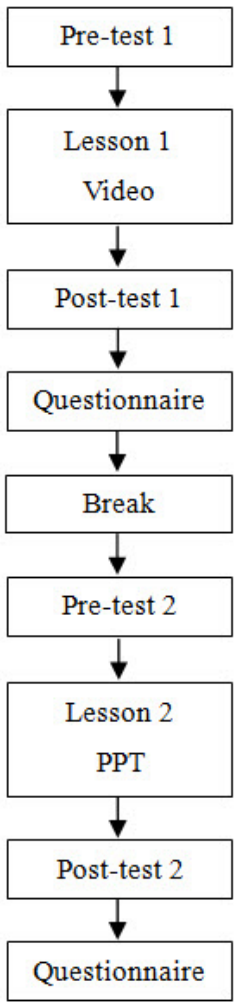

Figure 4: Process of our learning system 
The content of lesson 1 introduces $\mathrm{C}$ programming for control and covers the following two topics:

1) Introduction to $C$ programming for control

2) Programming style

The content of lesson 2 is basic of $\mathrm{C}$ programming for control and covers the following three topics:

1) Structure of a $C$ program

2) Developing a small program in $\mathrm{C}$

3) Inputting data and printing the results obtained from a $\mathrm{C}$ program for control.

The content of lesson 2 is more difficult than lesson 1 .

Examples of pre and post-test questions for lesson 1 are shown in Table 3. Since both consist of ten questions and each question has one point, the highest score is ten.

Our system uses servers and links to the Internet by such common web browsers as Internet Explorer, Chrome, and Firefox [12] (Figures 5 to 8). The procedures are described below:

1. Learners register when they first $\log$ onto the e-learning system. After logging in, personalized e-learning starts.

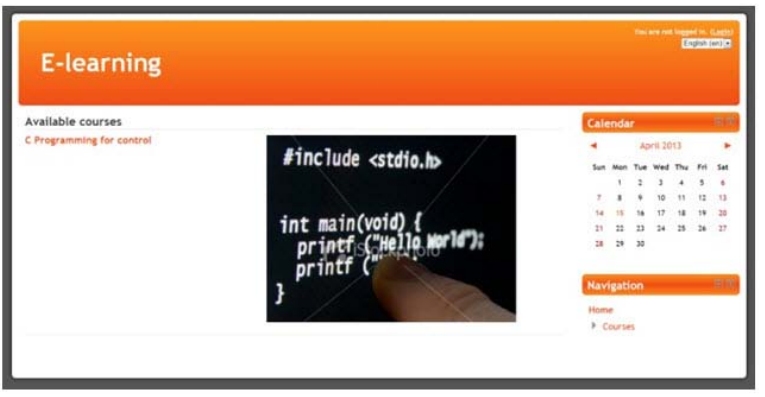

Figure 5: Example of interface design for first page

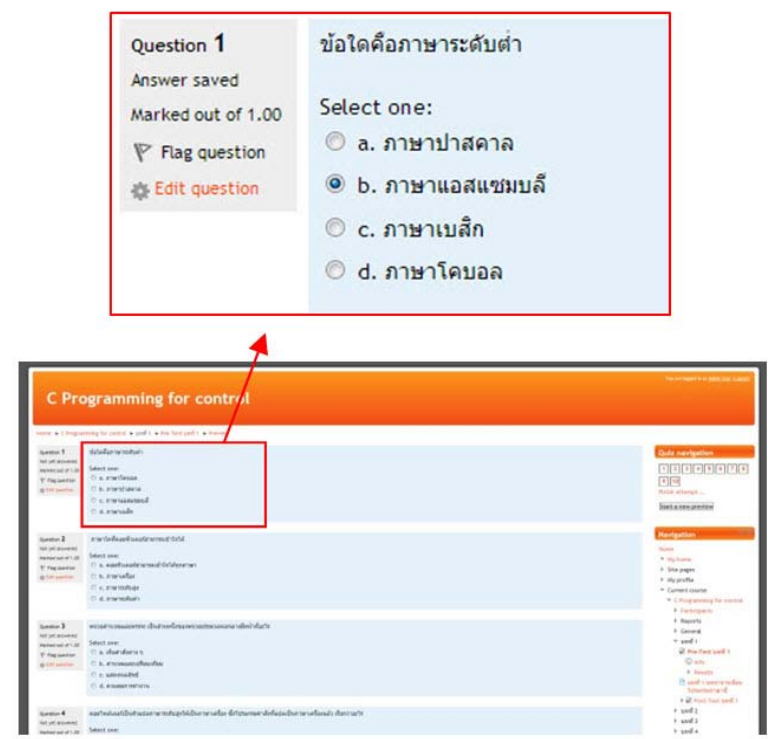

Figure 6: Example of interface design for pre-tests, post-tests and questionnaires

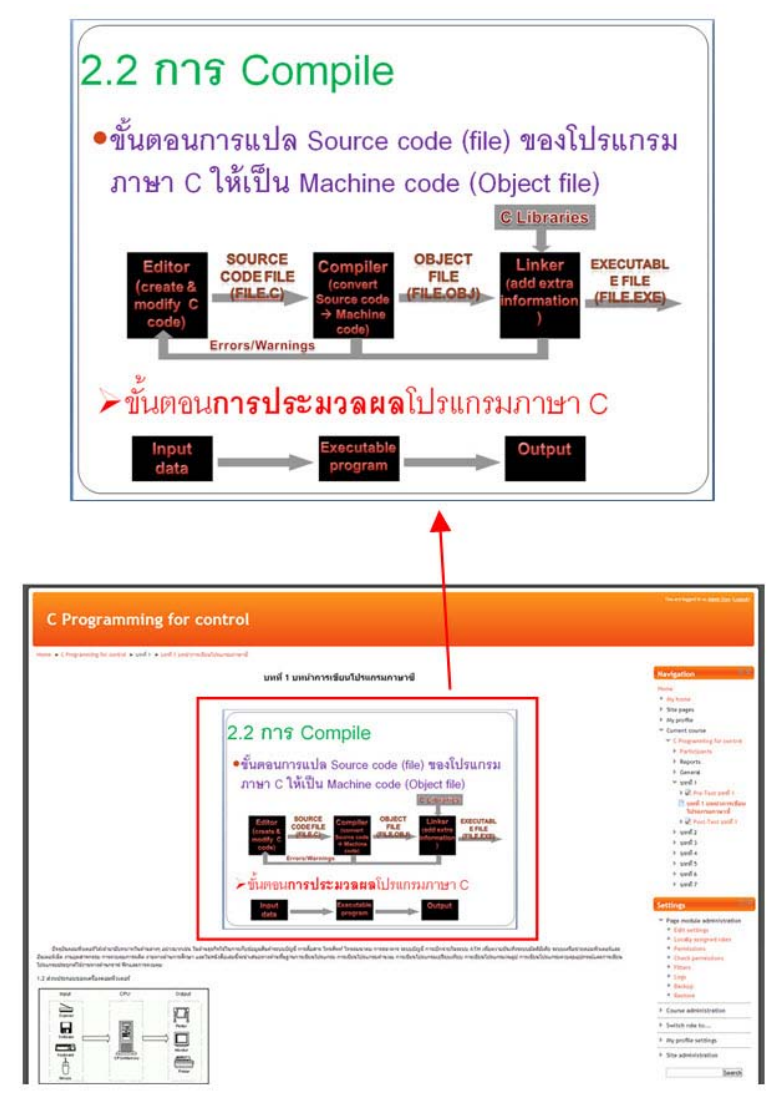

Figure 7: Example of interface design for PPT
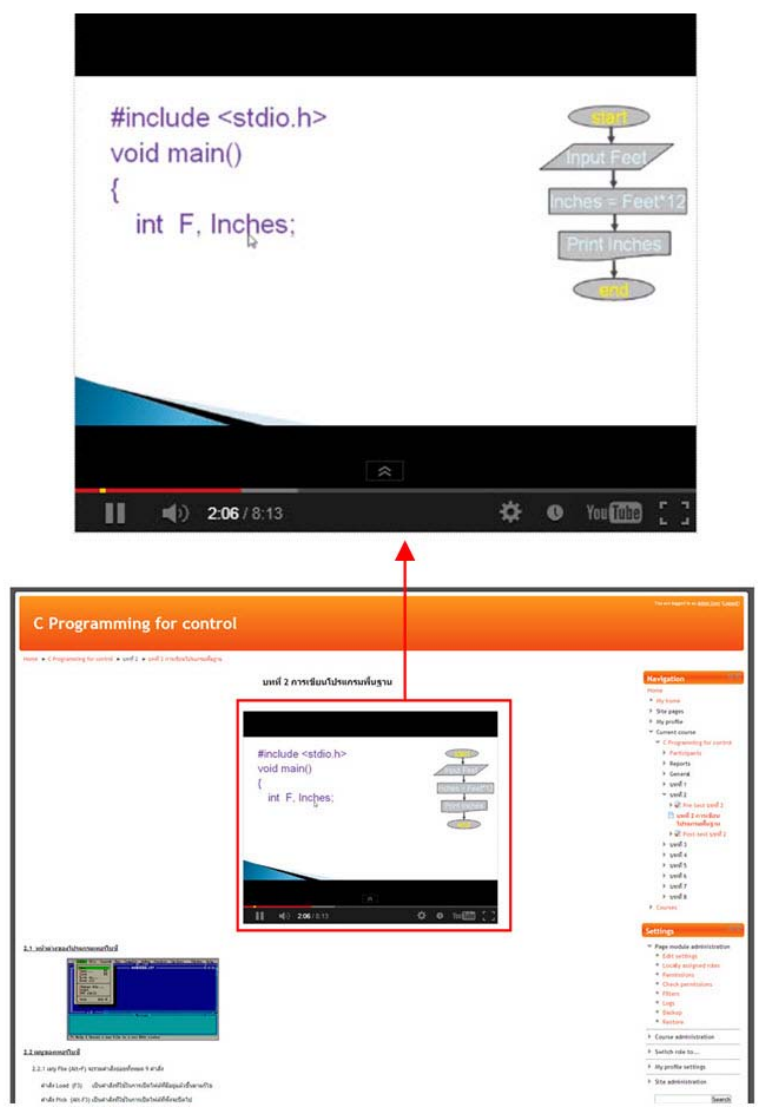

Figure 8: Example of interface design for video 
2. They take a pre-test within ten minutes before lesson 1 starts.

3. They learn lesson 1 of pattern I only one time. If they do not understand it, they can repeat lesson 1 to get additional explanation of the text content.

4. After finishing lesson 1, they take a post-test.

5. They answer a questionnaire.

6. They take a 10 minutes break.

Table 3: Examples of pre and post-test questions for lesson 1 (in Thai)

\begin{tabular}{|c|c|}
\hline \multicolumn{2}{|c|}{ Lesson 1 pre-test } \\
\hline Q\# & Content \\
\hline 1. & $\begin{array}{l}\text { Which is a low level language? } \\
\text { a. Cobalt } \\
\text { b. Assembly } \\
\text { c. Pascal } \\
\text { d. Basic }\end{array}$ \\
\hline 2. & $\begin{array}{l}\text { What language can computers understand? } \\
\text { a. All languages } \\
\text { b. High-level languages } \\
\text { c. Machine languages } \\
\text { d. Low-level languages }\end{array}$ \\
\hline 3. & $\begin{array}{l}\text { What is the function of the Arithmetic and Logic Unit as part } \\
\text { of the processor? } \\
\text { a. Collection of various commands. } \\
\text { b. Calculation and comparison. } \\
\text { c. Results. } \\
\text { d. Controls. }\end{array}$ \\
\hline 4. & $\begin{array}{l}\text { What is a program command called that compiles a high-level } \\
\text { language into a machine language? } \\
\text { a. Object program } \\
\text { b. Compiled program } \\
\text { c. Source program } \\
\text { d. Computer program }\end{array}$ \\
\hline 5. & $\begin{array}{l}\text { What should be stored as a start command for a computer } \\
\text { system in any part of the computer system? } \\
\text { a. ALU } \\
\text { b. CPU } \\
\text { c. RAM } \\
\text { d. ROM }\end{array}$ \\
\hline \multicolumn{2}{|r|}{ Lesson 1 post-test } \\
\hline 1. & $\begin{array}{l}\text { What is computer programming? } \\
\text { a. Convincing your computer to never freeze } \\
\text { b. Speeding up your computer } \\
\text { c. Setting the alarm on a computer } \\
\text { d. Telling your computer what to do through a special set } \\
\text { of instructions }\end{array}$ \\
\hline 2. & $\begin{array}{l}\text { Which of the following is NOT a software language? } \\
\text { a. C } \\
\text { b. C++ } \\
\text { c. Visual Basic } \\
\text { d. HTML }\end{array}$ \\
\hline 3. & $\begin{array}{l}\text { If you were to look at a machine language program, you would } \\
\text { see } \\
\text { a. Source code } \\
\text { b. A stream of binary numbers } \\
\text { c. English words } \\
\text { d. Circuits }\end{array}$ \\
\hline 4. & $\begin{array}{l}\text { Which of the following is NOT a web language } \\
\text { a. C++ } \\
\text { b. PHP } \\
\text { c. Javascript } \\
\text { d. HTML }\end{array}$ \\
\hline 5. & $\begin{array}{l}\text { Every C program begins execution at function } \\
\text { a. main }() \\
\text { b. \#include } \\
\text { c. Void } \\
\text { d. Compiler }\end{array}$ \\
\hline
\end{tabular}

Q\# : Question number
7. They take a pre-test before lesson 2 starts.

8. They learn lesson 2 of pattern I only one time. If they do not understand, they can repeat lesson 2 to get additional explanation of the text content.

9. After finishing lesson 2, they take a post-test.

10. They answer a questionnaire.

Our questionnaires asked 15 questions related to learner emotions in e-learning systems [11]. Participants answered on a 5-points Likert scale [13] (Table 4).

\subsection{Experiment Results and Discussion}

We conducted our experiments by equally dividing 60 Thai-Nichi Institute of Technology students into two groups for patterns I and II. Figure 9 shows a scene of the experiment.

\subsubsection{Pre-test and post-test results}

The results of the pre and post-test scores for learning lessons 1 and 2 are summarized in Table 5. From the statistical analysis results, the mean difference between the post and pre-test results of lesson 1's PPT (2.90) was significantly higher than that of its video $(2.63)(\mathrm{p}<.01)$.

The mean difference between the post and pre-test results of lesson 2's video (3.37) was significantly higher than that of its PPT $(3.17)(\mathrm{p}<.01)$

Table 4: Questionnaire items on 5-point Likert scale (in Thai)

\begin{tabular}{|c|l|c|}
\hline Q\# & \multicolumn{1}{|c|}{ Content } & $\begin{array}{c}\text { Related } \\
\text { emotion }\end{array}$ \\
\hline 1 & $\begin{array}{l}\text { The learning process increased my learning } \\
\text { attention. }\end{array}$ & Attention \\
\hline 2 & $\begin{array}{l}\text { Putting a multimedia performance into the } \\
\text { learning system motivated me to use it. }\end{array}$ & Motivation \\
\hline 3 & The learning system helped me learn better. & Satisfaction \\
\hline 4 & $\begin{array}{l}\text { I reduced my negative emotions after interact- } \\
\text { ing with the learning system. }\end{array}$ & $\begin{array}{l}\text { Negative } \\
\text { emotion }\end{array}$ \\
\hline 5 & $\begin{array}{l}\text { Interacting with the learning system increased } \\
\text { my positive emotions. }\end{array}$ & $\begin{array}{c}\text { Positive } \\
\text { emotion }\end{array}$ \\
\hline 6 & E-learning made my course more enjoyable. & Enjoy \\
\hline 7 & From time to time the courses were interesting. & Interest \\
\hline 8 & E-learning is satisfying. & Satisfaction \\
\hline 9 & Studying e-learning courses was often fun. & Enjoy \\
\hline 10 & I felt proud after finishing an e-learning course. & Satisfaction \\
\hline 11 & Some feature of e-learning were stressful. & Anxiety \\
\hline 12 & The e-learning courses were frustrating. & Frustration \\
\hline 13 & Using the e-learning courses was irritating. & Irritation \\
\hline 14 & Starting the e-learning course was scares me. & Scare \\
\hline 15 & $\begin{array}{l}\text { Using the e-learning system was sometimes } \\
\text { tiring. }\end{array}$ & Tiring \\
\hline
\end{tabular}

Q\# : Question number 
Table 5: Pre and post-test results

\begin{tabular}{|c|c|c|c|c|c|c|c|c|c|}
\hline \multirow[t]{2}{*}{ Lesson } & \multirow[t]{2}{*}{ Design } & \multicolumn{2}{|c|}{ Pre-test } & \multicolumn{2}{|c|}{ Post-test } & \multicolumn{2}{|c|}{$\begin{array}{c}\text { Differences between } \\
\text { Post-Pre tests }\end{array}$} & \multicolumn{2}{|c|}{ t-test } \\
\hline & & Mean & SD. & Mean & SD. & Mean & SD. & $\mathrm{t}$ & P-Value \\
\hline \multirow{2}{*}{1} & PPT & 4.63 & 1.82 & 7.53 & 1.27 & 2.90 & 1.80 & \multirow{2}{*}{11.919} & \multirow{2}{*}{$.000 * *$} \\
\hline & Video & 4.80 & 1.29 & 7.43 & 1.22 & 2.63 & 1.81 & & \\
\hline \multirow{2}{*}{2} & PPT & 4.83 & 1.68 & 8.00 & 1.36 & 3.17 & 1.80 & \multirow{2}{*}{38.980} & \multirow{2}{*}{$.000 * *$} \\
\hline & Video & 4.27 & 1.23 & 7.63 & 1.52 & 3.37 & 1.81 & & \\
\hline
\end{tabular}

\subsubsection{Lesson 1 results}

We conducted an independent-samples t-test to compare the results for learning lesson 1 between the PPT in Pattern I and the video in Pattern II for the questionnaire shown in (Table 6). We found the following significant difference in the scores for questions 11 to 15 between the PPT and the video at a $1 \%$ level:

- Q\#11: E-learning with PPT has features that caused more anxiety than e-learning with video.

- Q\#12: E-learning courses caused more learner frustration with PPT more than with video.

- Q\#13: Using the e-learning courses is more irritating with PPT than with video.

- Q\#14: Learners are more scared when starting an e-learning course with PPT than with video.

- Q\#15: Using the e-learning system was at times more tiring with PPT than with video.

On the other hand, we found no significant differences in the scores for questions 1 to 10 .

\subsubsection{Lesson 2 results}

We conducted an independent-samples t-test to compare the results for learning lesson 2 between PPT in Pattern II

Table 6: Learning lesson 1 results

\begin{tabular}{|c|c|c|c|c|c|c|}
\hline \multirow{2}{*}{ Q.\# } & \multicolumn{2}{|c|}{ PPT } & \multicolumn{2}{c|}{ Video } & \multirow{2}{*}{$\mathrm{t}$} & \multirow{2}{*}{ P-Value } \\
\cline { 2 - 5 } & Mean & SD. & Mean & \multicolumn{1}{c|}{ SD. } & & \\
\hline 1 & 3.67 & .606 & 3.47 & .776 & 1.112 & .271 \\
\hline 2 & 2.90 & .548 & 3.20 & .805 & -1.687 & .098 \\
\hline 3 & 3.57 & .504 & 3.50 & .630 & .453 & .652 \\
\hline 4 & 3.17 & .913 & 3.37 & .890 & -.859 & .394 \\
\hline 5 & 3.30 & .596 & 3.37 & .669 & -.408 & .685 \\
\hline 6 & 2.87 & .730 & 2.97 & .765 & -.518 & .606 \\
\hline 7 & 2.93 & .868 & 3.17 & .950 & -.993 & .325 \\
\hline 8 & 3.43 & .568 & 3.37 & .615 & .436 & .664 \\
\hline 9 & 3.07 & .583 & 3.20 & .484 & -.963 & .339 \\
\hline 10 & 3.97 & .669 & 3.73 & .740 & 1.282 & .205 \\
\hline 11 & 3.30 & .988 & 2.07 & 1.143 & 4.472 & $.000 * *$ \\
\hline 12 & 2.63 & .490 & 1.90 & .885 & 3.971 & $.000^{* *}$ \\
\hline 13 & 2.40 & .814 & 1.57 & .774 & 4.065 & $.000^{* *}$ \\
\hline 14 & 3.83 & .648 & 2.17 & 1.440 & 5.780 & $.000^{* *}$ \\
\hline 15 & 3.27 & .907 & 1.93 & 1.230 & 4.779 & $.000^{* *}$ \\
\hline
\end{tabular}

and video in Pattern I for the questionnaires shown in Table 7. We found a significant difference in the scores for questions 1, 2, 4, 5, 7, 13, and 14 between PPT and video at a $1 \%$ level. In addition, we found a significant difference in the scores for question 15 between PPT and video at a $5 \%$ level:

- Q\#1: The learning process increased the learning attention more with video than with PPT.

- Q\#2: Putting the multimedia performance on video motivated learners to use the system more than with PPT.

- Q\#4 and \#5: Video interaction increased their positive emotions and lowered their negative emotions more in the learning system than with PPT.

- Q\#7: Sometimes the course was more interesting with video than with PPT.

- Q\#13: Using the e-learning course was more irritating with PPT than with video.

- Q\#14: Learners are more scared when starting an e-learning course with PPT than with video.

- Q\#15: Using the e-learning system was at times more tiring with video than with PPT.

Table 7: Learning lesson 2 results

\begin{tabular}{|c|c|c|c|r|r|l|}
\hline \multirow{2}{*}{ Q.\# } & \multicolumn{2}{|c|}{ PPT } & \multicolumn{2}{c|}{ Video } & \multirow{2}{*}{$\mathrm{t}$} & \multirow{2}{*}{ P-Value } \\
\cline { 2 - 5 } & Mean & \multicolumn{1}{|c|}{ SD. } & Mean & \multicolumn{1}{c|}{ SD. } & & \\
\hline 1 & 2.47 & .571 & 3.97 & .809 & -8.297 & $.000^{* *}$ \\
\hline 2 & 2.63 & .556 & 3.70 & .837 & -5.816 & $.000^{* *}$ \\
\hline 3 & 3.30 & .915 & 3.17 & .699 & .634 & .529 \\
\hline 4 & 3.30 & .596 & 3.77 & .728 & -2.717 & $.009^{* *}$ \\
\hline 5 & 2.83 & .699 & 3.67 & .802 & -4.290 & $.000^{* *}$ \\
\hline 6 & 2.00 & .743 & 2.40 & 1.070 & -1.682 & .099 \\
\hline 7 & 1.50 & .630 & 2.23 & .817 & -3.893 & $.000^{* *}$ \\
\hline 8 & 2.10 & .803 & 1.87 & .571 & 1.297 & .200 \\
\hline 9 & 2.60 & 1.248 & 2.20 & .714 & 1.523 & .135 \\
\hline 10 & 1.93 & .640 & 2.40 & 1.102 & -2.006 & .051 \\
\hline 11 & 3.10 & .923 & 3.50 & .974 & -1.633 & .108 \\
\hline 12 & 3.60 & 1.003 & 3.27 & .521 & 1.615 & .114 \\
\hline 13 & 4.17 & .747 & 3.13 & .434 & 6.553 & $.000^{* *}$ \\
\hline 14 & 4.40 & .770 & 3.57 & .679 & 4.446 & $.000^{* *}$ \\
\hline 15 & 2.03 & .765 & 2.50 & .630 & -2.580 & $.012^{*}$ \\
\hline
\end{tabular}

$*: \mathrm{p}<.05$

$* *: \mathrm{p}<.01$

Q\# : Question number 


\subsubsection{Comparison of lessons 1 and 2}

We obtained the following from the results in Tables 6 and 7:

- Q\#1: The learning process with video increased the learning attention more than PPT in lesson 2. This may reflect that automatically running lesson2's video required learners to pay more attention than in lesson 1, because lesson 2'content was more difficult than lesson 1, as we already noted.

- Q\#2: In lesson 2, putting the multimedia performance into the learning system motivated learners more with video than with PPT. Future work will investigate which attributes in Table 2 affect motivation.

- Q\#4 and \#5: Interaction with the learning system with video increased learner positive emotions and lowered their negative emotions more with PPT in lesson 2. Future work will investigate which attributes affect positive and negative emotions.

- Q\#7: The course with video is more interesting than with PPT in lesson 2. Future work will investigate which attributes affect interest.

- Q\#11 and \#12: PPT caused more anxiety and frustration than the video in lesson 1. Future work will investigate which attributes affect anxiety and frustration.

- Q\#13 and \#14: Using the e-learning course is more irritating with PPT than with the video both in lessons 1 and 2. Starting the e-learning course with PPT is more scared than with the video both in lessons 1 and

2. Future work will investigate which attributes affect irritation and scare.

- Q\#15: Using the e-learning system was more tiring with the video than with the PPT in lesson 2. Perhaps automatically running the video is more tiring than PPT where the learners can proceed to the next slide by themselves. Perhaps the cause is the fact that lesson 2's content was more difficult than lesson 1 as we already described.

\subsubsection{Relation between test and questionnaire results}

We obtained the following from the results of Tables 5, 6, and 7:

- Lesson 1: The scores and emotions do not match. This may be because lesson 1's content was more easier than lesson 2's.

- Lesson 2: The learner emotions directly reflect the test scores because lesson 2's content was more difficult than lesson 1's.

These results show the importance of the emotional aspects of e-learning systems.

\section{CONCLUSION}

We designed a new prototype e-learning system and tools to avoid inefficient affective states, such as boredom or anxiety. Our new e-learning system consists of four modules: learners, instructors, servers, and analysis of learner emotions. We analyzed learner emotions based on Russell's circumplex model to describe the user's emotion space.

We built a prototype of an e-learning system and experimentally evaluated it by pre and post-test scores and questionnaires about learner emotions.

We obtained the following results by comparing the test scores and the questionnaire results.

- For lesson 1, the PPT scores are higher than the video scores. However, PPT induces more anxiety, frustration irritation, scared, tiring during learning. We do not conclude that PPT is better than video.

- For lesson 2, its video scores are higher than PPT. It also increases attention, motivation, and interest more than PPT. We conclude that video is more effective than PPT.

- Emotional aspects are important in e-learning.

In general, an e-learning system's effect is measured by such scores as the differences between pre and post-tests. However, our experimental results suggest that we should consider account emotional aspects in the design interfaces or the contents of e-learning systems.

In future work, we will design a new e-learning system with the following features:

- Sending feedback to an LMS based on learner emotions.

- Detection of learner emotions using biological signals.

We want to evaluate learner emotions by biological signals instead of questionnaires because we cannot detect learner emotions in real-time.

\section{ACKNOWLEDGEMENTS}

This research was supported by the Shibaura Institute of Technology, Japan and the Thai-Nichi Institute of Technology, Thailand. We also thank all the participants in our experiments.

\section{REFERENCES}

[1] Nadire, C. and Ala'a, M. M.: Computer aided evaluation of learning management systems, World Conferences on Educational Sciences 2009, pp.426430 (2009). 
[2] Shen, L., Wang, M., and Shen, R.: Affective e-Learning: Using "Emotional" Data to Improve Learning in Pervasive Learning Environment. Educational Technology \& Society, 12(2), pp.176189 (2009).

[3] Hammond, D.L., Rosso, J., Austin, K., Orcutt, S., and Martin, D.: The Learning Classroom: Theory Into Practice. In: Stanford University, p.90 (2003).

[4] Goleman, D.: Emotional Intelligence: Why It Can Matter More Than IQ. In: New York: Bantam. (1995).

[5] Khan, B. H.: A Framework for Web-based Learning. In: B. H. Khan (Ed.), Web-based Training. Englewood Cliffs, NJ: Educational Technology Publications (2011).

[6] Kittanakere, L. N., Lakshmisri, L. N. R., and Nirmal, K. S.: An Emotional System for Effective and Collaborative e-Learning. In: ACHI 2011 The Fourth International Conference on Advances in Computer-Human Interactions, pp.260-266 (2011).

[7] Russell, J.A.: A Circumplex Model of Affect. In: Journal of Personality and Social Psychology, vol.39, pp.1161-1178 (1980).

[8] Kaiser, R., and Oertel, K.: Emotions in HCI - An Affective E-Learning System. In: The HCSNet Workshop on the Use of Vision in HCI (VisHCI 2006), p.56 (2006).

[9] Hu D.: Design and Implementation of E-Learning Performance Evaluation System, 2008 International Conference on Computer Science and Software Engineering (IEEE), pp.376-380 (2008).

[10] Joanne, A., Lorraine, P., Luis, S., Yvonne, S., Peter, M., Fleure, G., and Giovanni, A.: Development and Impact Evaluation of an E-Learning Radiation Oncology Module, In: Journal of Radiation Oncology Biology Physics, 82(3), pp.e573-e580 (2012).

[11] Chin-Yeh, W., Shu-Yu, K., Hui-Chun, C., He-Yun, T., and Gwo-Dong, C.: E-learning system design with humor and empathy interaction by virtual human to improve students' learning, Proceedings of the 18th International Conference on Computers in Education. Putrajaya, Malaysia: Asia-Pacific Society for Computers in Education. (ICCE), pp.615-622 (2010).

[12] Tanenbaum, S. A.: Computer Networks, PrenticeHall, Inc., pp.10, 17 (1996).
[13] Izumiya A., Ohkura M., and Tsuchiya F.: The Evaluation of Pharmaceutical Package Designs for the Elderly People, Proceedings of the Symposium on Human Interface 2009 on Human Interface and the Management of Information. Information and Interaction. Part II: Held as part of HCI International, (2009).

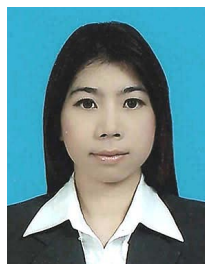

\section{Saromporn CHAROENPIT}

Saromporn Charoenpit is currently an enrolled as a doctoral student in Functional Control Systems, Graduate School of Engineering and Science, the Shibaura Institute of Technology (SIT), Japan. She received her certification in Electrical and Electronics (1997), B.S. (2002) degree in Industrial Physics and Medical Instrumentation, and M.S. (2007) degree in Management Information Systems from King Mongkut's University of Technology North Bangkok, Thailand. Her current research interests include emotional, e-learning, and Kansei engineering.

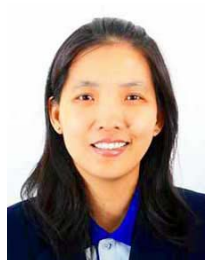

\section{Salinla CHEVAKIDAGARN}

Salinla Chevakidagarn is working at the faculty of Information Technology, Thai-Nichi Institute of Technology, Bangkok Thailand, since 2008. Her main lecture class is about database system. From 2001 to 2007, she worked as a lecturer and had classes about Artificial Intelligence, Structure Programming, Object-oriented Programming at the Department of Computer Science, Faculty of Science, Prince of Songkla University, Thailand. Her research experience at Department of Computer Science, Prince of Songkla University, Songkla, Thailand is about Data filtering technique for neural networks forecasting of Artificial Intelligence Research Laboratory. She received her M.S. in Information Technology from King Mongkut's University of Technology Thonburi, Thailand, with the special project study entitled "Electrocardiography Analysis Using Neural Network". Her Bachelor degree is Bachelor of Science in Mathetics-computer from Mahidol University, Thailand.

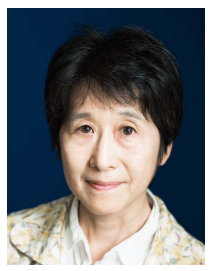

\section{Michiko OHKURA}

Michiko Ohkura is a professor of College of Engineering at Shibaura Institute of Technology (SIT). She received her B.S. (1976) M.S. (1978) in Mathematical Engineering and Ph.D (1995) in Advanced Interdisciplinary Studies from the University of Tokyo, respectively. She worked for Central Research Laboratory, Hitachi, Ltd. and other companies, and joined SIT in 1999. Her research interests include safety of medical usage, interactive systems and Kansei information processing especially by measuring biological signals. She is now a director of Japan Society of Kansei Engineering, and Virtual Reality Society of Japan. 